\title{
Performance Evaluation of Biodegradable Oilfield Scale Inhibitors for Calcium Carbonate Scales
}

Ohimor, Evuensiri Onoghwarite ${ }^{1}$, Anigboro, Oghale Endurance ${ }^{2}$, Anih, Christiana Edward ${ }^{3}$ and Ononiwu, Prosper Ikechukwu ${ }^{4}$

${ }^{\mathbf{1}}$ Federal University of Petroleum Resources, Effurun, Delta State, Nigeria, Phone No: +2348033888418: E-mail address: ohimor.evuensiri@ fupre.edu.ng

${ }^{2}$ Federal University of Petroleum Resources, Effurun, Delta State, Nigeria, Phone No: +2348038932763: E-mail address: anigboro22@yahoo.com

${ }^{3}$ Federal University of Petroleum Resources, Effurun, Delta State, Nigeria, Phone No: +2348057278841: E-mail address:edward.christiana@ fupre.edu.ng

${ }^{4}$ Michael Okpara University of Agriculture, Umudike, Abia State, Nigeria, Phone No: +2347036331364: E-mail address: prince3iyke75@gmail.com

\section{ABSTRACT}

Scale formation is a serious oil field problem that is detrimental to water injection systems. The most common means ofreducing and preventing scale deposition is through the use of scale inhibitors. The research is aimed at evaluating two environmentally friendly scale inhibitors, polyaspartic acid (PAS) and polymer of maleic acid (PMA) origin; in terms of their inhibition performance on $\mathrm{CaCO}_{3}$ scaling water. Both biodegradable scale inhibitors (PAS and PMA) were evaluated through compatibility test, thermal stability at $130^{\circ} \mathrm{C}$ evaluation and static jar test. Comparability tests perfomed at temperatures of $25^{\circ} \mathrm{C}$ and $90^{\circ} \mathrm{C}$ for the PAS and PMA,did not indicate any precipitationat the various scale inhibitors concentrations studied. The result of the thermal stability tests on the two scale inhibitors at $130^{\circ} \mathrm{C}$ indicated that the two inhibitors PAS and PMA were thermally stable, since no precipitates were formed. Accordingly, the scale inhibition performanceevaluation was carried out using static jar test. The scale inhibition efficiency for PAS on calcium carbonate scaling water was $87 \%$ with a treatment dose of $80 \mathrm{ppm}$ and at $80^{\circ} \mathrm{C}$, while at the same treatment dose of $80 \mathrm{ppm}$ resulted in $69 \%$ scale inhibition efficiency at $90^{\circ} \mathrm{C}$. Also, for PMA the scale inhibition efficiency on calcium carbonate scaling waterwas $70 \%$ with a treatment dose of $80 \mathrm{ppm}$ and a $80^{\circ} \mathrm{C}$ while at the same treatment dose of $80 \mathrm{ppm}$ a61\% scale inhibition efficiency was achievedat $90^{\circ} \mathrm{C}$. Finally, based on set criteria, the PAS scale inhibitor was adjudged to have passed all evaluation criteria at $80 \mathrm{ppm}$, thereby proving more effective in performance than the PMA scale inhibitor.

Keywords: Inhibition performance, Oilfield scaling, Biodegradable scale inhibitor, Static Jar Tests, Calcium carbonate

Corresponding Author: Ohimor E. O.

\section{INTRODUCTION}

Oilfield scaling is the precipitation and accumulation of crystals of insolublesalts over time, blocking and hindering fluid flow through pipelines, valves, pumps; it usually results from a mixture of incompatible aqueous phases in oil processing systems [1]. Calcium carbonates are common scale-deposit minerals in water treatment plants and liquid handling vessels inOil and gas industry, causing significant increase in the production cost with significant reduction in production rates and equipment damages [2]. 
Specialty chemicals of various chemistries for scale prevention, referred to as Scale Inhibitors, are now being applied in the water management system of many industries. Also, overthe past several decades, the oilfield sector has been increasingly concerned about the environmental impact of the Scale Inhibitors, as well as other specialty chemicals in use. The most commonly used commercial Scale Inhibitors are represented by three chemical families: polyphosphates (hexametaphosphate (HMP), tripolyphosphate (TPP), organophosphonates (aminotris methylenephosphonic acid), ATMP; 1-hydroxyethane-1,1-bisphosphonic acid), HEDP; 2phosphonobutane 1,2,4-tricarboxylic acid (PBTC), etc.), and organic polyelectrolytes (polyacrylates (PA); polycarboxysulfonates). At the same time, phosphorus-based inhibitors are hardly biodegradable and persist for many years after their disposal, which usually leads to eutrophication problems [3,4,]. However, the commonly used inhibitors based on phosphates or phosphonates are known to have toxic effects on aquatic organisms or cause eutrophication problems $[3,5]$.

Increasing environmental concerns of the governmental authorities and discharge limitations have forced the specialty chemical industries and oilfield companies to move toward "green scale inhibitors" that are non-toxic, readily biodegradable and have minimal environmental impact. Intensive efforts are currently being applied recently to develop the "green" alternatives to organophosphonates and nonbiodegradablepolyacrylates[3, 6, 7, 8]. Several new scale inhibitors meeting these requirements were lately tested with regard to their inhibitory efficiency[9, 10, 11]. Among these novel inhibitors are such chemicals as polymaleates (PMA), polyaspartates (PASP), and polyepoxysuccinates (PESA), as well as their various derivatives including copolymers with polyacrylates (PA), are the most promising [12].

Thus, it is necessary to seek an acceptable balance between biodegradability and inhibitory performance of these scale inhibitors. It is important to note that the new scale inhibitors should have acceptable levels of performance at cost-effective dose rates. This requirement raises a problem of reliable tests, which engenders a correct "old red" and "novel green" inhibitors efficiency comparison[8, 13, 14, 15, 16]. The performance of scale inhibitors can be evaluated by the following two kinds of tests. The jar or bottle test is a static test of a fluid batch in a reactor (static batch test) and is widely used for inhibitor efficiency testing. The tube blocking test is carried out under dynamic conditions within a tube [17]. These tests result in the quantification of the inhibitory effect by determining the minimum inhibitor concentration (MIC), which is defined as the concentration of the inhibitor required to prevent a predefined change of a scaling indicating physical quantity over a certain time.

The incipient technique to the laboratory evaluation of scale inhibitors performance to prevent scale deposition was described. Thus, the inhibition performance of the two biodegradable inhibitors in preventing calcite scale were evaluated experimentally utilizing compatibility test, as well assessing the effects of physical factors on the inhibition performance of the biodegradable inhibitors. The compatibility test enables the monitoring of calcite scale formation in the absence and presence of scale inhibitors.

\section{MATERIALS AND METHODS}

\subsection{Materials}

Liquid form polymer based oilfield scale inhibitors, polyaspartic acid sodium salt (PASP); CAS Number. 181828-06-8, and polymer of maleic acid (PMAS); CAS Number 26099-092, were sourced from a Chemical and Reagent Laboratory, in Nigeria. The two oilfield scale inhibitors were $100 \%$ of PASP and $100 \%$ PMA respectively, as purchased. 


\subsection{Preparation of the brine solutions and compositions}

The brine solutions forevaluation of the scale inhibition performance of the scale inhibitors were prepared as follows:

The Cation solution (Calcium-containing brine): $\mathrm{NaCl}=33.00 \mathrm{~g} / \mathrm{l}, \mathrm{CaCl}_{2} \cdot 2 \mathrm{H}_{2} \mathrm{O}=12.15 \mathrm{~g} / \mathrm{l}$, $\mathrm{MgCl}_{2} \cdot 6 \mathrm{H}_{2} \mathrm{O}=3.68 \mathrm{~g} / \mathrm{l}$.

The Anion solution (Bicarbonate-containing brine): $\mathrm{NaCl}=33.00 \mathrm{~g} / \mathrm{l}, \mathrm{NaHCO}_{3}=7.36 \mathrm{~g} / \mathrm{l}$, $\mathrm{Na}_{2} \mathrm{SO}_{4}=0.03 \mathrm{~g} / 1$.

\subsection{Performance Evaluation Tests}

Table 2. 1: Evaluation criteria

\begin{tabular}{lll}
\hline TEST & PASS & FAIL \\
\hline $\begin{array}{l}\text { pH for 100\% product } \\
\text { Thermal stability at }\end{array} \quad \begin{array}{l}\text { Clear with or without change in } \\
\text { the colour }\end{array}$ & $\begin{array}{l}\text { Precipitation } \\
\mathbf{1 3 0}^{\circ} \mathbf{C}\end{array} \quad \begin{array}{l}\text { with } \\
\text { Compatibility } \\
\text { water }\end{array}$ \\
& $\begin{array}{l}\text { Clear solution for all ranges of } \\
\text { concentration }(50 \mathrm{ppm}, 100 \mathrm{ppm}, \\
1 \%, 5 \%, 10 \%, 25 \%, 50 \% \text { and } \\
90 \%) \text { at both } 25^{\circ} \mathrm{C} \text { and } 90^{\circ} \mathrm{C}\end{array}$ & $\begin{array}{l}\text { Slightly Hazy, Hazy or } \\
\text { precipitated solution }\end{array}$ \\
&
\end{tabular}

\subsection{1 pH measurements}

The $\mathrm{pH}$ values of two biodegradable scale inhibitors of polymaleates (PMA), polyaspartates (PAS) origins, were measured with $\mathrm{pH}$ meter calibrated with two buffer solutions of $\mathrm{pH}=$ 4.0, and 10.0 .

\subsubsection{Thermal stability}

Thermal stability is an important property for high temperature oil well application of scale inhibitors. Thermal degradation of molecules may severely affect their scale inhibiting efficiency. Hence, the thermal stability of the two biodegradable scale inhibitors of polymaleates (PMA), polyaspartates (PASP) origins, were tested at $130^{\circ} \mathrm{C}$. A $15 \mathrm{ml}$ volume of each inhibitor under investigation were placed in respective transparent bottles and observed forclearness then photographed before being subjected to the thermal test. The inhibitors were, each transferred into a high pressure high temperature stainless steel vessels and left in the oven at $130^{\circ} \mathrm{C}$ for $24 \mathrm{hrs}$. After $24 \mathrm{hrs}$ of heat subjection the vessels were removed from the oven and left to cool for $2 \mathrm{hrs}$ in a dessicator. Thereafter, the inhibitors were transferred again to their respective transparent bottles and checked for any change in the appearance that could occurr due to high temperature, and then the bottles were photographed again after being exposed to a high temperature.

\subsubsection{Compatibility testing of inhibitors}

The compatibility of water with the two biodegradable scale inhibitors of polymaleates (PMA), polyaspartates (PAS) origins, were tested.

The brine was filtered with a 45 micron filter paper prior to being used for the compatibility test. One of the scale inhibitorsto be evaluatedwas mixed with brine to cover a whole range of concentrations (0ppm, 50ppm, $100 \mathrm{ppm}, 1 \%, 5 \%, 10 \%, 25 \%, 50 \%$ and 90\%) in transparent glass tubes of total volume of $15 \mathrm{~mL}$. All concentration tubes were checked for any sign of incompatibility (haziness, precipitation) and photographs were taken for all test tubes to be an evidence for the test. The tests were carried out at both ambient and $90^{\circ} \mathrm{C}$ temperatures. The above steps were repeated with the other inhibitors to be evaluated. 


\subsection{Static Jar Tests}

Following NACE Standard TM0374-2007 procedure[18], the static jar test for evaluation of scale inhibiting properties of the scale inhibitors was conducted.

The brine solutions for calcium carbonate deposition inhibition performance evaluation were saturated using $\mathrm{CO}_{2}$ at room temperature while the upper space of the test flask is $30-35 \mathrm{ml}$. In the first step, a certain quantity of scale inhibitor was weighed into the Erlenmeyer flask; in the second step, $50 \mathrm{~mL}$ of cationic solution added, shaken uniformly; and in the third step, $50 \mathrm{ml}$ of anionic solution added, and then plugged by plastic stopper wrapped with polyethylene (PE) film. Wrap the entire flask by PE film, and then pack it tightly using cellotape. Finally, the Erlenmeyer flasks were placed in the oven for $24 \mathrm{hrs}$ at $70^{\circ} \mathrm{C}$.

Inhibitor efficiency was calculated based on remaining $\mathrm{Ca}^{2+}$ ions in solution according to the following equation.

Percentage inhibition $(\%)=\frac{\mathrm{C} 2-\mathrm{C} 0}{\mathrm{C} 1-\mathrm{CO}} \times 100 \%$

where $\mathrm{C}_{2}$ is the mass concentration of $\mathrm{Ca}^{2+}$ ions after inhibitor functions, $\mathrm{C}_{1}$ is the mass concentration of $\mathrm{Ca}^{2+}$ ions in the solution of which $50 \mathrm{ml}$ deionized water without anions was added in the third step, $\mathrm{C}_{0}$ was the mass concentration of $\mathrm{Ca}^{2+}$ ions of the solution with no inhibitor. The test of the mass concentration of $\mathrm{Ca}^{2+}$ ion will also follow the method specified by the standard TM0374-2007.

In this method, the cations and anions of the formation water, which was taken from a producing well, were determined and the results inputted into a computer program sheet [19], which will then calculate the amount of cations and anions for each sample. This underscores the use of brine in the test procedure for the evaluation of scale inhibitors by determining the calcium ion before and after the precipitation for the blank (without any inhibitor addition), to calculate the efficiency of scale inhibitor at different temperature and different dosage rate, the samples were kept in an oven $24 \mathrm{hrs}$ for precipitation at required temperature and dosage.

\subsection{Effects of Physical Factors on the Inhibition Performance of Inhibitor Temperature}

Thescale forming tendency is known to be affected by temperature, hence the scale inhibitor has different inhibition ability at different temperatures. Thus, the inhibition performance of the inhibitor at 60 and $80^{\circ} \mathrm{C}$ were also studied in this work.

\section{pH value}

Thestudy of inhibitor's performance on calcium carbonate was carried out with the following $\mathrm{pH}$ values; $6.0,6.5,7.0,7.5,8.0,8.5$, and 9.0. The $\mathrm{pH}$ of the solution was adjusted by boraxboric acid buffer solution. The solutions for calcium carbonate evaluation were saturated with $\mathrm{CO}_{2}$ at room temperature after adjusting to the required $\mathrm{pH}$ value.

\section{RESULTS AND DISCUSSIONS}

\section{1 pH measurement}

The $\mathrm{pH}$ measurement of the scale inhibitors, PAS and PMA, were 8.0 and 6.0, respectively as shown in Table 3.1, the pass criteria should be greater than 5 this means that the two inhibitors pass in this test.

Table 3.1: pH values of evaluated scale inhibitors

\begin{tabular}{lll}
\hline Inhibitor code & pH Value & Pass criteria $(>5)$ \\
\hline PAS & 8.0 & Pass \\
PMA & 6.0 & Pass \\
\hline
\end{tabular}




\subsubsection{Thermal stability}

The result of the thermal stability test of the two scale inhibitors before and after exposure to a temperature of $130^{\circ} \mathrm{C}$ shows that both inhibitors, PAS and PMA did not result in precipitate, hence, they are reported as being thermal stable. The visual observations are presented in Figure 3.1, which shows at ambient temperature, a clear pale yellow liquid for inhibitor PAS and clear light amber liquid, for inhibitor PMA. Then after exposure to a temperature of $130^{\circ} \mathrm{C}$, both retained their clear appearances. However, the colour of PMA became dark amber. It was observed that there were no precipitationsfrom any of the two inhibitors at all the temperatures, hence both inhibitors, passed the thermal stability test.

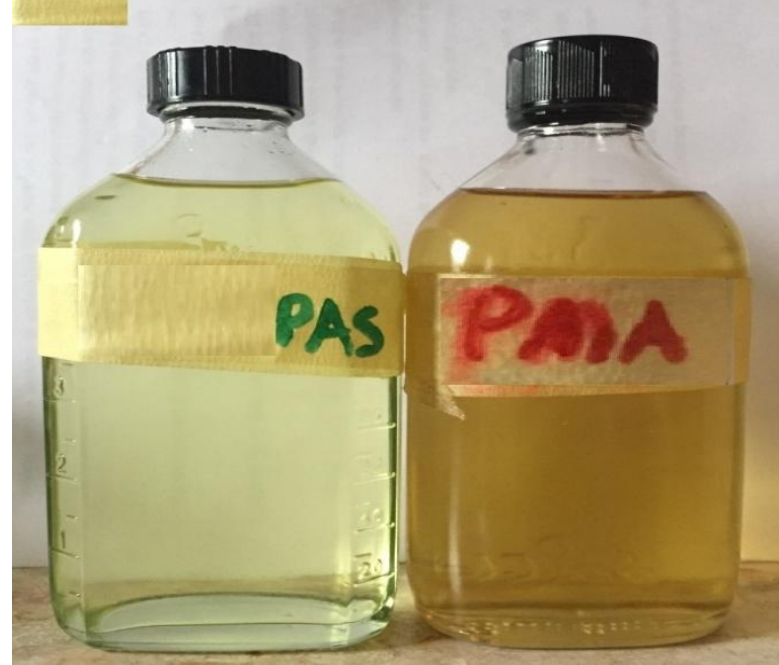

Before heating

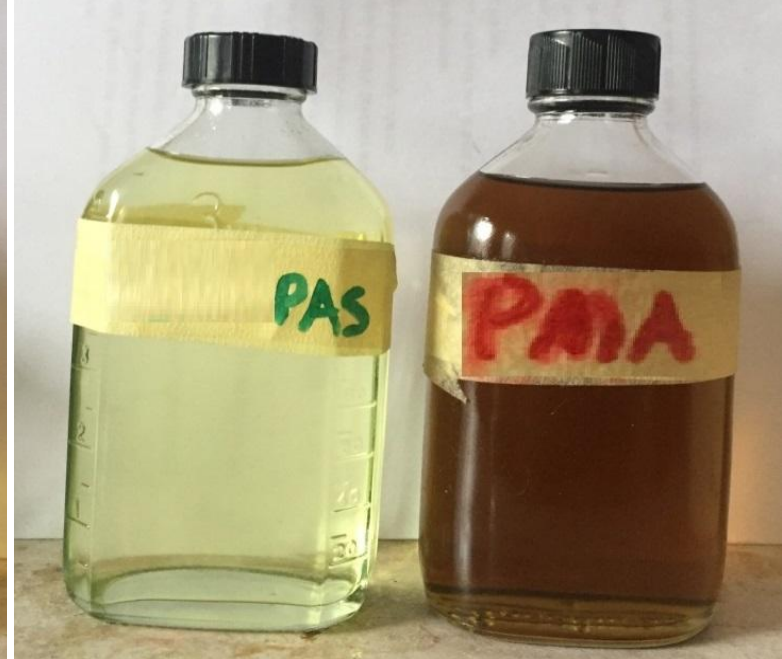

After 24Hrs heating at $130^{\circ} \mathrm{C}$

Figure 3.1: Visual observation of inhibitors PAS and PMA before and after heating.

\subsubsection{Compatibility test with brine}

The result of the compatibility test of the two scale inhibitors with brine at both ambient and $90^{\circ} \mathrm{C}$ were tabulated in Tables 3.3 and 3.4. The recorded results were taken immediately and after $24 \mathrm{hrs}$ at $25^{\circ} \mathrm{C}$, also taken after $15 \mathrm{~min}$ at $90{ }^{\circ} \mathrm{C}$. The obtained results indicated that no precipitation took place at any scale inhibitors concentrations and temperatures. A very clear solution was observed immediately at $25^{\circ} \mathrm{C}$ temperature for scale inhibitor PAS and the clarity did not changed after $24 \mathrm{hrs}$ at the same temperature; the clarity still did not change even after $15 \mathrm{~min}$ at $90^{\circ} \mathrm{C}$. The same phenomenon was observed with scale inhibitor PMA.

Table 3.3: Compatibility test of scale inhibitor (PAS) with filtered brine

\begin{tabular}{llll}
\hline Inhibitor concentration & & $\mathbf{2 5}^{\circ} \mathbf{C}$ & $\mathbf{9 0} \mathbf{C}$ \\
\cline { 2 - 4 } & $\mathbf{0 ~ h r}$ & After $\mathbf{2 4} \mathbf{~ h r s}$ & After 15 min \\
\hline $0 \mathrm{ppm}$ (Blank) & $\mathrm{C}$ & $\mathrm{C}$ & $\mathrm{C}$ \\
$50 \mathrm{ppm}$ & $\mathrm{C}$ & $\mathrm{C}$ & $\mathrm{C}$ \\
$100 \mathrm{ppm}$ & $\mathrm{C}$ & $\mathrm{C}$ & $\mathrm{C}$ \\
$1 \%$ & $\mathrm{C}$ & $\mathrm{C}$ & $\mathrm{C}$ \\
$5 \%$ & $\mathrm{C}$ & $\mathrm{C}$ & $\mathrm{C}$ \\
$10 \%$ & $\mathrm{C}$ & $\mathrm{C}$ & $\mathrm{C}$ \\
$25 \%$ & $\mathrm{C}$ & $\mathrm{C}$ & $\mathrm{C}$ \\
$50 \%$ & $\mathrm{C}$ & $\mathrm{C}$ & $\mathrm{C}$ \\
$90 \%$ & $\mathrm{C}$ & $\mathrm{C}$ & $\mathrm{C}$ \\
\hline
\end{tabular}

Key: $\mathrm{C}=$ Clear, $\mathrm{H}=$ Hazy, PPT = Precipitate 


\begin{tabular}{llll}
\hline Table 3.4: Compatibility & test of scale inhibitor (PMA) with filtered brine \\
\hline & \multicolumn{2}{c}{$\mathbf{2 5}^{\circ} \mathbf{C}$} & $\mathbf{9 0} \mathbf{C}$ \\
\cline { 2 - 4 } & $\mathbf{0 ~ h r}$ & After 24 hrs & After 15 min \\
\hline 0 ppm (Blank) & $\mathrm{C}$ & $\mathrm{C}$ & $\mathrm{C}$ \\
$50 \mathrm{ppm}$ & $\mathrm{C}$ & $\mathrm{C}$ & $\mathrm{C}$ \\
$100 \mathrm{ppm}$ & $\mathrm{C}$ & $\mathrm{C}$ & $\mathrm{C}$ \\
$1 \%$ & $\mathrm{C}$ & $\mathrm{C}$ & $\mathrm{C}$ \\
$5 \%$ & $\mathrm{C}$ & $\mathrm{C}$ & $\mathrm{C}$ \\
$10 \%$ & $\mathrm{C}$ & $\mathrm{C}$ & $\mathrm{C}$ \\
$25 \%$ & $\mathrm{C}$ & $\mathrm{C}$ & $\mathrm{C}$ \\
$50 \%$ & $\mathrm{C}$ & $\mathrm{C}$ & $\mathrm{C}$ \\
$90 \%$ & $\mathrm{C}$ & $\mathrm{C}$ & $\mathrm{C}$ \\
\hline
\end{tabular}

Key: $\mathrm{C}=$ Clear, $\mathrm{H}=$ Hazy, PPT $=$ Precipitate

\subsection{Evaluation of Scale Inhibition Performance}

From Figure 3.4, the trend tagged PAS shows that, with increase in the inhibitor treatment dose, the inhibition efficiency increased. However, when the treatment dose reached a critical value, the inhibition rate attained a maximum value, after which the inhibition rate exhibited a plateau or a slight decrease tendency. For the calcium carbonate inhibition performance evaluation, the inhibition rate increased sharply higher than $50 \%$ with increase in the treatment dose from 20 to $70 \mathrm{ppm}$. At the optimum dosage of $70 \mathrm{ppm}$, an inhibition efficiency of $95 \%$ on calcium carbonate was obtained. Under the evaluations, it can be seen from the trend tagged PMA in Figure 3.4, that the optimum treatment dose on calcium carbonate at $70^{\circ} \mathrm{C}$ is $60 \mathrm{ppm}$ (with an inhibition efficiency of $84 \%$ ). Also, the inhibition rate increased sharply higher than $50 \%$ with increase in the treatment dose from 20 to $60 \mathrm{ppm}$. It is clearly demonstrated that the inhibitor PAS exhibited a relatively good inhibition performance on calcium carbonate.

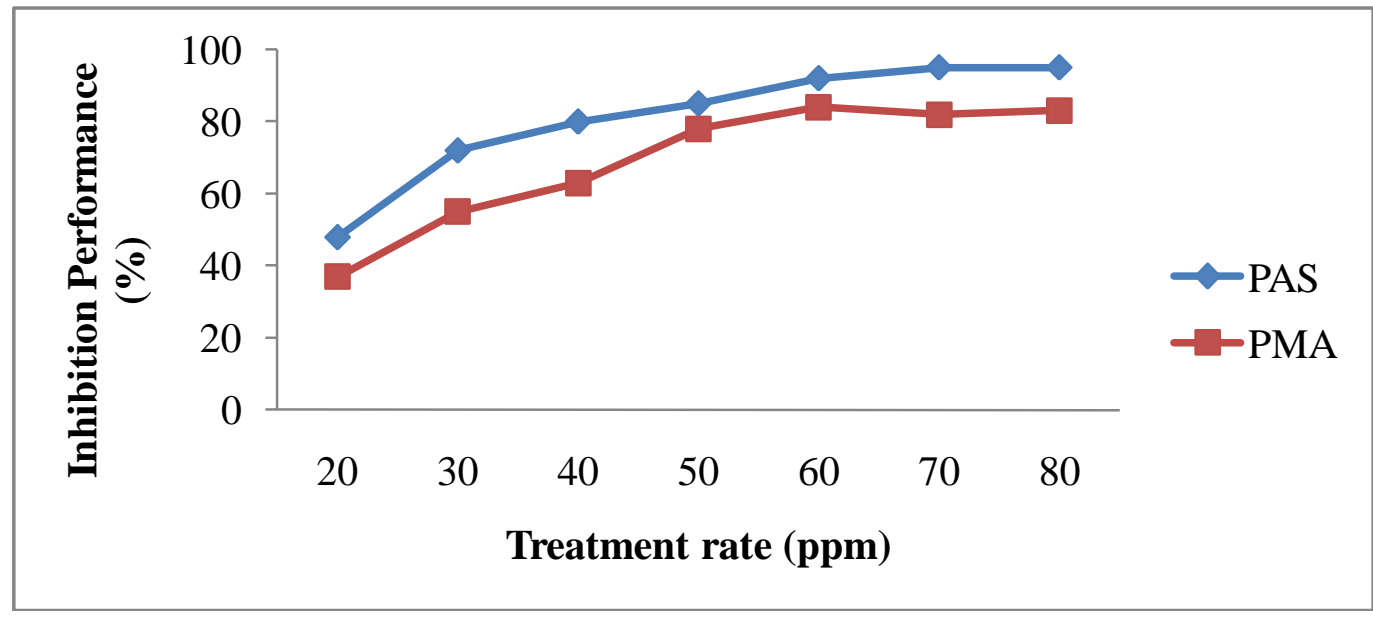

Figure 3.4 Scale inhibitors performance on calcium carbonate at $70^{\circ} \mathrm{C}$

\subsection{Effects of temperature on the inhibition performance of the Scale inhibitor}

As can be seen from the Figure 3.3, the scale inhibition efficiency for PAS on calcium carbonate was $87 \%$ with the treatment dose of $80 \mathrm{ppm}$ at $80^{\circ} \mathrm{C}$ while at the same treatment dose of $80 \mathrm{ppm}$, but $90^{\circ} \mathrm{C}$, an inhibition efficiencyof $69 \%$ was achieved. 
Also, for PMA trend, in Figure 3.4, the scale inhibition efficiency on calcium carbonate attained $70 \%$ with the treatment dose of $80 \mathrm{ppm}$ at $80^{\circ} \mathrm{C}$ while at the same treatment dose of $80 \mathrm{ppm}$, but $90^{\circ} \mathrm{C}$, resulted in $61 \%$ scale inhibition efficiency.

This may be attributed to the fact that high temperatures favours theformation of calcium carbonate crystals, as a result an increase in scale inhibitor treatment dose is necessary to obtain a better efficiency. Also, the fact that there is more polymer adsorption on the calcium carbonate crystal nuclei at higher temperature may account for this phenomenon. On the overall, at higher temperatures, additional inhibitor dosage is needed to maintain a high inhibition rate for calcium carbonate control.

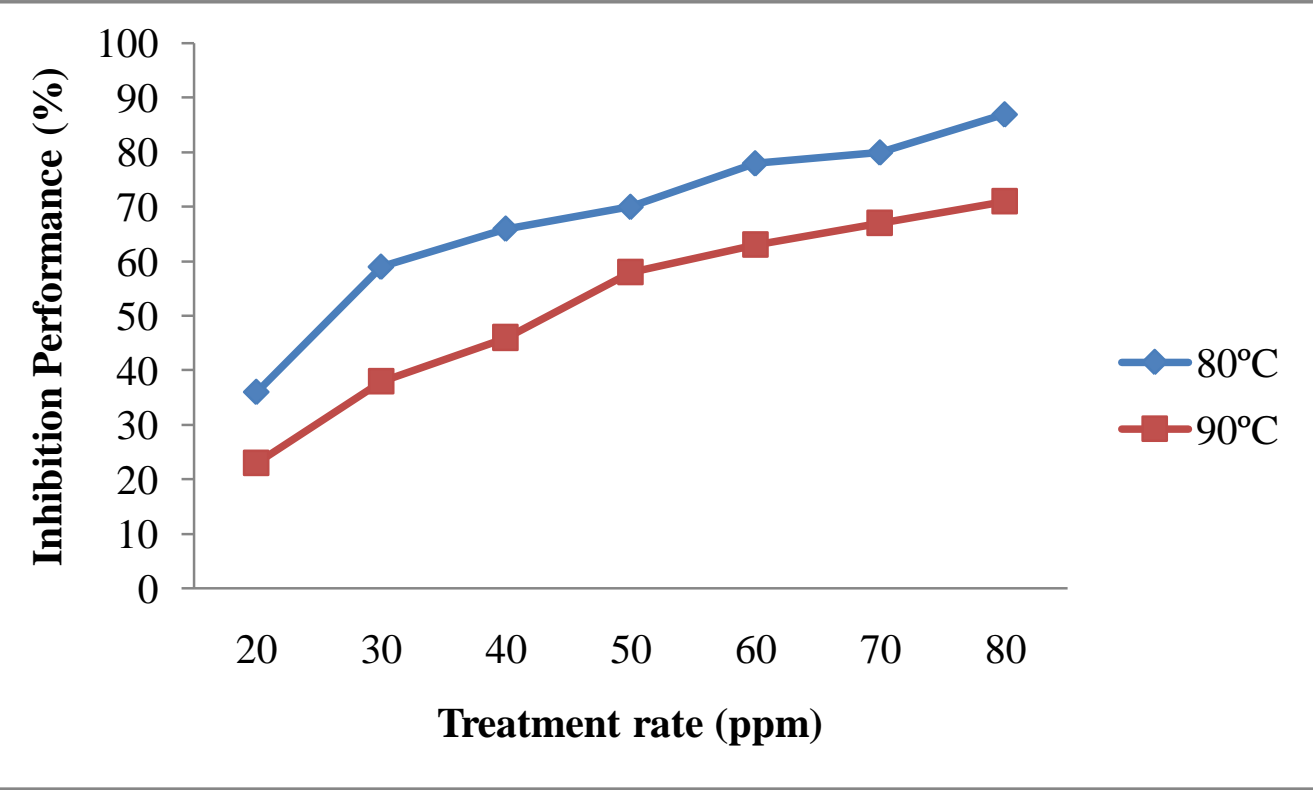

Figure 3.5: Effect of temperature on the inhibition performance of $\mathrm{PAS}$ on $\mathrm{CaCO}_{3}$

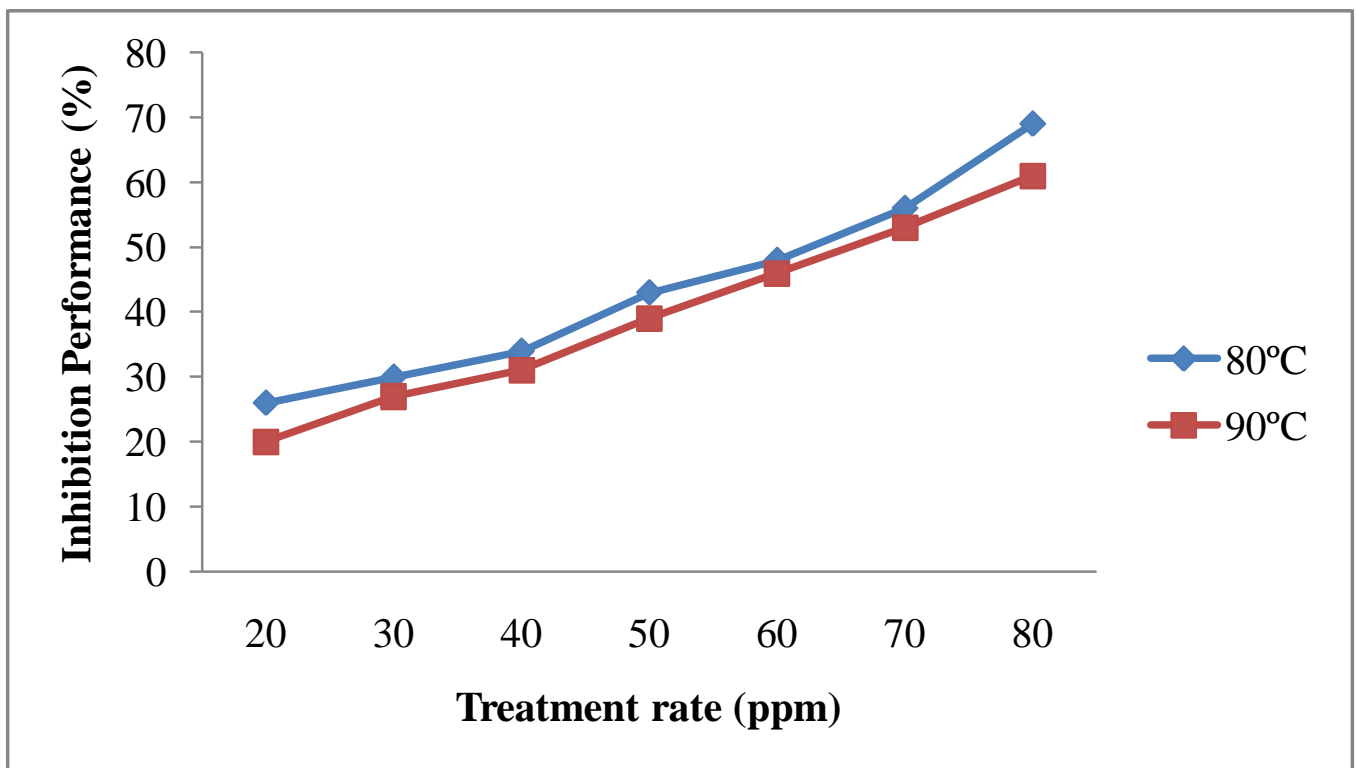

Figure 3.6: Effect of temperature on the inhibition performance of $\mathrm{PMA}^{\text {on }} \mathrm{CaCO}_{3}$

\subsection{Effect of $\mathrm{pH}$ on the Inhibition Performance on $\mathrm{CaCO}_{3}$ at $70 \mathrm{ppm}$ of $\mathrm{PAS}$ and 60ppm of PMA}

The effect of $\mathrm{pH}$ on the scale inhibitor performance is shown below; Figure 3.7. When the $\mathrm{pH}$ is 7.0 for both the PAS and PMA trends, the scale inhibitors presented a good inhibition 
efficiency on calcium carbonate, also, a slight decrease in inhibition efficiency when the $\mathrm{pH}$ is higher than 7.5 was observed. The reason may be due to the fact that an increased concentration of hydroxyl ions will react readily with bicarbonate ions, therebyreleasing more carbonate ions and hence more scale precipitation is observed.

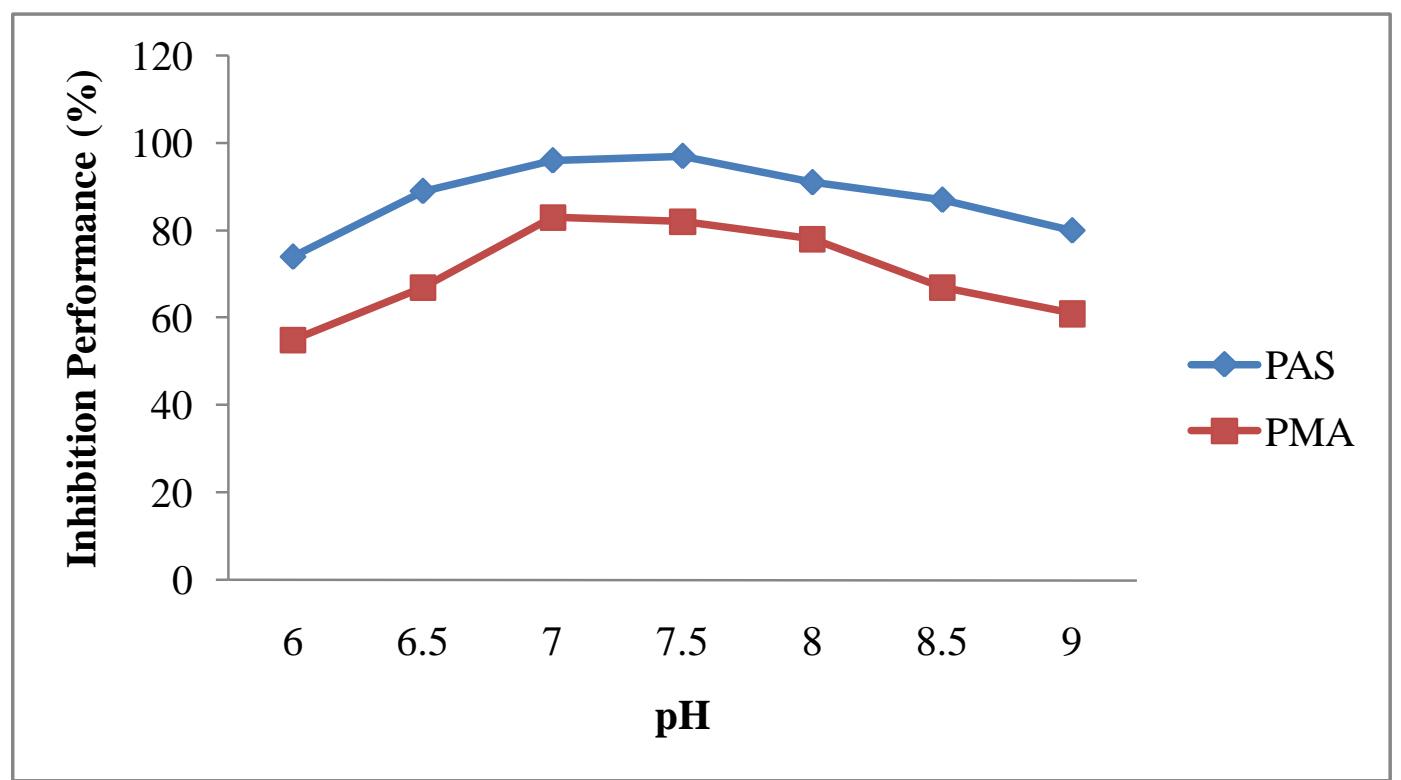

Fig 3.7: Effect of $\mathrm{pH}$ on the inhibition performance on $\mathrm{CaCO}_{3}$ at 70ppm of $\mathrm{PAS}$ and 60ppm of PMA

\section{CONCLUSION}

Two biodegradable polymer based oilfield scale inhibitors were prepared, and there inhibition efficiencies on calcium carbonate, were evaluated. It was observed that inhibition efficiencies higher than $95 \%$ can be achieved. A higher dosage of scale inhibitor is necessary for achieving high inhibition efficiency on calcium carbonate deposition at higher temperature and neutral $\mathrm{pH}$. Thus, it was determined that thePAS based scale inhibitor, has $95 \%$ inhibition efficiencyfor preventing $\mathrm{CaCO}_{3}$ scale formation.

The results of the compatibility test of the two scale inhibitors with brine at both ambient and higher temperature did not indicate any precipitation at any of the tested scale inhibitors concentrations and temperatures. The experimental work was carried out to study $\mathrm{CaCO}_{3}$ scaling inhibition by the PAS and PMA based inhibitors for oilfield produce water. Based on the experimental findings the PAS based scale inhibitor can be pilot tested for oilfield application.

\section{REFERENCES}

[1] W. F.Wayne, Z, Murtaza,N. Wolf (Editor) and H.Ryan (Editor) (2008). Formation, removal, and inhibition of inorganic scale in the oilfield environment.Society of Petroleum Engineers.

[2] B.Liang, K.Pan,L. Li, E. P. Giannelis andB.Cao, (2014)."High performance hydrophilic pervaporation composite membranes for water desalination" Desalination.347: 199_ 206.

[3] D.Hasson, H. Shemerand A.Sher, (2011). "State of the art of friendly 'green' scale control inhibitors: a review article," Industrial and Engineering Chemistry Research, 50:12, 7601-7607. 
[4] M.Feiner, S. Beggel,N.Jaeger and J.Geist (2015). "Increased RO concentrate toxicity following application of antiscalants - acute toxicity tests with the amphipods Gammaruspulexand Gammarusroeseli," Environmental Pollution, 197: 309- 312.

[5] S.Lattemann and T.Höpner (2008).Environmental Impact and Impact Assessment of Seawater Desalination.Desalination, 220: 1-15.

[6] Y. M.Al-Roomi and K. F.Hussain (2015) "Application and evaluation of novel acrylic based CaSO4 inhibitors for pipes," Desalination,355: 33-44.

[7] H.Shemer and D.Hasson (2015). "Characterization of the inhibitory effectiveness of environmentally friendly anti-scalants," Desalination and Water Treatment, 55:13, pp. 3478-3484.

[8] H.Wang, G.Liu, J.Huang, et al., (2015).Performance of an environmentally friendly antiscalant in $\mathrm{CaSO}_{4}$ scale inhibition, Desalination and Water Treatment, 53(1): 8-14.

[9] M.M.Reddy and A.R.Hoch (2000). Calcite Crystal Growth Rate Inhibition by Polycarboxylic Acids.J. Colloid Interface Sci., 235, 365-370.

[10] S.Baraka-Lokmane,K.S.Sorbie,N.Poisson and P.Lecocq (2008).Application of Environmentally Friendly Scale Inhibitors in Carbonate Coreflooding Experiments. SCA2008-05, International Symposium of the Society of Core Analysts, Abu Dhabi, UAE.

[11] D.J.Choi,S.J.You and J.G.Kim (2002). Development of an Environmentally Safe Corrosion, Scale, and Microorganism Inhibitor for Open Recirculating Cooling Systems. Mater. Sci. Engin.A335, 228-236.

[12] K. I.Popov, G.Rudakova,V. E.Larchenko,M.Tusheva,S.Kamagurov,J.Dikareva and N.Kovaleva (2016). A Comparative Performance Evaluation of Some Novel (Green) and Traditional Antiscalants in Calcium Sulfate Scaling. Advances in Materials Science and Engineering, Hindawi Publishing Corporation. Vol. 2016, 10

[13] S. A.Ali, I. W.Kazi and F.Rahman, (2015). "Synthesis and evaluation of phosphate-free antiscalants to control $\mathrm{CaSO}_{4} \cdot 2 \mathrm{H}_{2} \mathrm{O}$ scale formation in reverse osmosis desalination plants," Desalination, 357: 36-44.

[14] D.Liu, W.Dong, F.Li, F.Hui and J.L'edion (2012). "Comparative performance of polyepoxysuccinic acid and polyaspartic acid on scaling inhibition by static and rapid controlled precipitation methods," Desalination, 304: 1-10.

[15] Z.Amjad and P. G.Koutsoukos (2014). "Evaluation of maleic acid based polymers as scale inhibitors and dispersants for industrial water applications," Desalination, vol. 335:1, pp. 55-63.

[16] Y.Zhao, L.Jia, K.Liu, P.Gao, H.Ge and L.Fu (2016). "Inhibition of calciumsulfate scale by poly (citric acid)," Desalination, 392, pp. 1-7.

[17] B.Bazin, N.Kohler and A.Zaitoun (2005).Some Insights Into the Tube Blocking Test Method To Evaluate the Efficiency of Mineral Scale Inhibitors.SPE 96560, SPE Annual Technical Conference, Dallas, TX.

[18] NACE Standard TM0374 (2007), (formerly TM0374 2001). Item No. 21208.

[19] J.E.Oddo, and M.B.Tomson (1994). "Why Scale Forms in the Oil Field and Methods To Predict It". SPE Production \& Facilities.9 (01): 47-54. 